\title{
Ganho de Peso e Evolução do Rebanho de Queixadas Selvagens em Sistemas de Criação Semi-extensivo e Extensivo, em Reserva de Cerrado ${ }^{1}$
}

\author{
Maria de Lourdes de Oliveira Andrade Figueira², Célia Regina Orlandelli Carrer³, \\ Paulo Bezerra Silva Neto4
}

\begin{abstract}
RESUMO - A utilização de comedouros automáticos com milho em grão foi testada como técnica para efetuar recaptura, marcação e manejo de queixadas (Tayassu pecari) reintroduzidas em área de Cerrado. Através desta técnica pôde-se comparar o ganho de peso de animais manejados em sistema extensivo (em liberdade) e em sistema semi-extensivo (restritos a uma área de 15 ha), bem como verificar aspectos da biologia reprodutiva da espécie. O manejo de queixadas através do sistema extensivo, demonstrou proporcionar um maior ganho de peso aos animais. Os comedouros automáticos com milho em grão, além de se mostrarem eficientes para a atração e agregação dos queixadas, proporcionou uma suplementação de energia. Através da marcação e recaptura dos indivíduos conseguiu-se verificar que esses animais se reproduzem durante todo o ano, gerando 1,57 filhotes /fêmea/parto, com diferenciação entre sexos de 50\%. A produtividade bruta no sistema semi-extensivo foi de 1,4 e a fecundidade bruta de 0,6 . A adoção do sistema extensivo para o manejo de queixadas, pode ser uma solução para a exploração sustentável da espécie, principalmente em regiões onde esse recurso é utilizado como fonte de subsistência através da caça ilegal.
\end{abstract}

Palavras-chave: queixada, Tayassu pecari, animal silvestre, manejo, sistema semi-extensivo e extensivo, reprodução

\section{Weight Gain and Evolution of a Wild White-Lipped Peccaries under Extensive and Semi-Extensive Systems, on a Savanna Area}

\begin{abstract}
The use of automatic feed barrel with grain corn as a methodology to mark, recapture and management of white-lipped pecaries (Tayassu pecari) reintroduced on a Savanna area located at Mato Grosso do Sul State was tested. Using this technique we could compare the weight gain managing animals on extensive (freedom on the area) and semi-extensive systems (restricted to a 15 ha area), and examine reproductive biology aspects of this specie. The management of white-lipped peccaries on the extensive system provided a greater weight gain to the animals. The automatic feed barrel with grain corn showed to be efficient to attract and aggregate the whitelipped peccaries but also provided supplemental energy. Using the mark and recapture method we could note that this animals reproduce all over the year, breeding 1,57 pig-lets/female/parturition, with the proportion between sex of 50\%. Gross productivity was 1,4 and gross fecundity $=0,4$. The adoption of extensive systems to manage white-lipped peccaries could be a solution to sustainable exploration of this specie at places where this resource is explored as a subsistence source through illegal hunting.
\end{abstract}

Key Words: white-lipped peccaries, Tayassu pecari, wild animal, management, extensive and semi-extensive system, reproduction

\section{Introdução}

A fauna silvestre tem sido utilizada há décadas como fonte de proteína animal, pelas populações indígenas e rurais do interior do Brasil. Apesardas legislações proibitivas, a caça tem sido o meio utilizado para esta exploração, que aliada a supressão dos habitats, vem causando perdas de recursos naturais muito pouco conhecidos.

Os queixadas (Tayassu pecari) podem ser exemplificados como um desses recursos, pois estiveram durante anos entre as espécies mais exploradas através da atividade de caça na América Latina (Redford \& Robinson, 1991), por possuírem carne entre as mais apreciadas e o couro apresentar altos valores de venda e de demanda no mercado internacional.

Dentre as três espécies de pecarídeos (Tayassuidae) que habitam a região neotrópica, o queixada é considerado o maior ungulado, nas Américas do Sul e Central, vivendo em grupos de até 200 indivíduos (Sowls, 1984).

O conhecimento atual sobre a biologia dos queixadas deriva principalmente de estudos realizados

\footnotetext{
${ }^{1}$ Parte da dissertação de Mestrado em Qualidade e Produtividade Animal da primeira autora, apresentada à FZEA/USP.

2 Bióloga/pesquisadora do IBAMA - FZEA/USP, Departamento de Ciências Básicas, caixa postal 23, Pirassununga-SP, CEP: 13635-900.

E.mail: Ifcaf@uninet.com.br

${ }^{3}$ Professora doutora do Departamento de Ciências Básicas/FZEA/USP - orientadora. E.mail: recarrer@usp.br

${ }^{4}$ Agrônomo/diretor-presidente da NPC, caixa postal 188, Iguape-SP, CEP:11920-000. E.mail:ongnpc@hotmail.com
} 
por Kiltie (1982) e Kiltie \& Terborgh (1983) que examinaram a separação de nichos entre os queixadas e os catetos (Tayassu tajacu), baseados em mecanismos e morfologia da mandíbula de espécimes de museu, e descreveram alguns aspectos da ecologia comportamental desses animais, através de sinais deixados por deslocamentos de grupos e do número de visitas destes a um local determinado. Bodmer (1995) analisou o conteúdo estomacal de animais procedentes da caça e estimou densidades populacionais utilizando esta técnica. A quantificação foi feita através de transectos, que são trilhas especialmente confeccionadas no campo para avistamento e contagem de espécies. Sowls (1984) forneceu uma descrição do comportamento de queixadas através de observações de um grupo de 60 indivíduos na região sudeste do Brasil, enquanto Mayer \& Wetzel (1987) revisaram esta literatura. Gottdenker \& Bodmer (1998) estudaram a reprodução e a produtividade de queixadas na Amazônia peruana e estudos sobre o manejo sustentado da espécie foram desenvolvidos por Bodmer (1995) no noroeste do Peru. Aspectos quanto a reprodução desta espécie em cativeiro foram reportados por Roots (1966) e estudos sobre a criação em cativeiro de queixadas foram desenvolvidos por Nogueira-Filho \& Lavorenti (1997).

Essesúltimos estudos demonstraram que os queixadas apresentaram potencial para serem explorados racionalmente através de sua criação em cativeiro. Esta criação já vem sendo realizada em algumas propriedades na Argentina e no Brasil, com a expectativa de que atendam a demanda da carne e do couro e, em conseqüência, diminuam a caça ilegal e predatória.

O manejo sustentado de populações selvagens também poderia ser uma alternativa para a exploração adequada da espécie, no entanto, o estabelecimento de técnicas e metodologias próprias para o manejo devem ser testadas, bem como, os estudos sobre a biologia dos queixadas devem ser intensificados.

Neste trabalho, comparou-se o manejo de queixadas em sistemas semi-extensivo e extensivo e determinou-se alguns parâmetros da sua biologia, objetivando a obtenção de informações que possam servir de subsídios para um manejo mais racional da espécie.

\section{Material e Métodos}

Área de estudo

O estudo foi realizado na Fazenda Cisalpina, localizada no município de Brasilândia, Estado do
Mato Grosso do Sul, entre as coordenadas $21^{0} 15^{\prime} \mathrm{S}$ e $51^{\circ} 54^{\prime} \mathrm{W}$. O clima é caracterizado como tropical úmido, do tipo AW, segundo a classificação de Köppen, com uma estação seca e fresca, definida de abril a setembro e outra chuvosa e quente, de outubro a março. A temperatura média anual nos últimos cinco anos foi de $24,1^{\circ} \mathrm{C}$.

Um mosaico de vegetações com fisionomia de Cerrado caracteriza a área, sendo 1.519 ha $(14,4 \%)$ de várzea, 5.732 ha $(54,4 \%)$ de campos e 3.289 ha $(31,2 \%)$ de mata mesófila, composta de árvores de porte médio e grande, formando grandes manchas, que variam de 30 a 150 metros de largura, entremeadas por áreas de campos e várzeas sazonalmente inundáveis.

Foram introduzidos na fazenda, a partir de setembro de 1998, cinco grupos de queixadas, assim distribuídos: grupo 1 - 16 indivíduos (4 machos e 12 fêmeas, sendo uma prenhe), grupo 2 - 16 indivíduos (6 machos e 10 fêmeas, sendo uma prenhe), grupo 3 - 19 indivíduos (9 machos e 10 fêmeas, sendo 5 prenhes), grupo 4 - 13 indivíduos (3 machos e 10 fềmeas, sendo 5 prenhes) e grupo 5 - 18 indivíduos ( 9 machos e 9 fêmeas).

O diagnóstico quanto a prenhez das fêmeas, tanto na introdução dos animais quanto nas recapturas, foi efetuado através da verificação de sinais externos, tais como o aumento de tamanho do ventre e do úbere. Nesta espécie observou-se também que as fêmeas prenhes permanecem com uma mancha preta na região da glândula de cheiro, localizada na parte dorsal anterior. Normalmente essa glândula se apresenta com uma cor amarelada.

O grupo 4 foi mantido em uma área cercada de 15 ha e os demais grupos foram soltos em diferentes pontos da área estudada. Os animais eram procedentes de capturas efetuadas numa fazenda localizada aproximadamente a $150 \mathrm{~km}$ ao sul da área experimental, também no Mato Grosso do Sul, que foi totalmente inundada com a formação do Reservatório da Usina Sérgio Motta.

Os animais antes de serem liberados foram pesados, identificados quanto ao sexo e a classe de idade. Para a definição das classes de idade, utilizou-se uma técnica adaptada de Schaller (1983), estabelecendose que indivíduos de 0 a $10 \mathrm{~kg}$ são classificados como filhotes, de 10 a $20 \mathrm{~kg}$ são jovens, de 20 a $30 \mathrm{~kg}$ são subadultos e acima de $30 \mathrm{~kg}$ são adultos. Os indivíduos foram também marcados individualmente com microchips (transponder) na região da cernelha (região dorsal, logo atrás da cabeça) e com brincos numerados numa das orelhas.

R. Bras. Zootec., v.32, n.1, p.191-199, 2003 
Instalações

O piquete utilizado no sistema de manejo semiextensivo foi formado em uma área de 15 ha totalmente cercada por um alambrado com tela de malha $10 \mathrm{~cm} \mathrm{X} 10 \mathrm{~cm}$, fio 12", com mourões dispostos em intervalos de $3,00 \mathrm{~m}$ e altura de $1,50 \mathrm{~m}$, e com um portão de madeira de $3,00 \mathrm{~m}$ de comprimento e 1,50 $\mathrm{m}$ de altura. Na base das telas, sobre o solo e entre os mourões, foram colocados troncos de madeira, de forma a dificultar a fuga dos animais. No interior do piquete foram colocadas dois comedouros automáticos, distantes aproximadamente $1.000 \mathrm{~m}$ um do outro. Ainda dentro deste piquete, foi construído um brete fixo para possibilitar o manejo.

Os comedouros automáticos constituíam-se de um tambor de plástico com tampa de rosca e capacidade de $50 \mathrm{~kg}$. Nesse tambor foi efetuado um furo no fundo de $3 / 4$ de polegada mais $0,5 \mathrm{~cm}$ de diâmetro. Dentro do tambor foi adaptada uma estrutura de ferro, composta de um tripé, com um cano no centro, de diâmetro inferior ao furo do tambor, por onde o cano saiu. Esse tambor foi então suspenso, de forma que o cano ficasse a uma altura de cerca de $10 \mathrm{~cm}$ do solo. Nessa posição, os comedouros possibilitaram que o milho em grão caísse automaticamente quando o animal tocasse o focinho no aparelho.

A estrutura do brete fixo foi construída para possibilitar a captura e o manejo dos animais e, para atraí-los, no seu interior foi instalado um comedouro automático. O brete apresentava forma circular, com diâmetro de 7,50 m, confeccionado com mourões dispostos a intervalos de $1,50 \mathrm{~m}$, alambrado com malha 2" e fio 12 " e altura de 1,50 m. Em toda a base do alambrado foram colocadas toras de madeira. $\mathrm{O}$ brete situado no piquete possuia duas portas do tipo guilhotina, para entrada dos animais, e uma porta comum, todas da mesma altura da cerca e largura de $0,80 \mathrm{~m}$. Dentro do brete a "seringa" proporcionou a retenção dos animais numa área menor, após serem capturados, permitindo que fossem retirados um a um para serem manejados. Os bretes fixos instalados fora do piquete, foram confeccionados com toras de madeira umas amarradas às outras, formando também uma área circular, sendo que para a entrada dos animais apresentavam uma porta do tipo basculante, medindo 2,00 x $1,50 \mathrm{~m}$.

O sistema semi-extensivo foi caracterizado por dispor de uma área com uma nascente de água e composta de $80 \%$ de mata (cerradão) e de $20 \%$ de gramíneas nativas, cercada em toda a sua extensão, onde os animais além de desfrutarem da alimentação natural, receberam uma suplementação de milho em grão, fornecida através de dois comedouros automáticos. Neste piquete foi introduzido, em 30/11/98, um grupo de queixadas constituído de 13 animais, aproximadamente um indivíduo por hectare, sendo 3 machos e 10 fêmeas, das quais cinco se encontravam prenhes na oportunidade da introdução.

O sistema extensivo foi definido como sendo aquele cujos grupos de queixadas ficaram livres, na área da fazenda (10.540 ha), utilizando as áreas de mata, campo e várzea. Os animais foram introduzidos em grupos de 15 a 17 indivíduos a partir do mês de setembro. Para permitir que os animais fossem recapturados e manejados foram utilizados 22 comedouros automáticos com milho, dispostos num setor da fazenda com predominância de mata e colocados preferencialmente na borda destas (com uma distância aproximada de $2.000 \mathrm{~m}$ entre cada um), a fim de possibilitar a adaptação dos grupos a esse novo ambiente e para que os animais se habituassem a freqüentar estes locais.

Foram introduzidos nesta área quatro grupos de queixadas, o Grupo 1 e Grupo 2 em 14/09/98, e o Grupo 3 e Grupo 5 em 20/10/98, totalizando 69 indivíduos (28 machos e 41 fêmeas).

Os comedouros foram instalados no mês de julho de 1998, objetivando verificar a presença de animais na área experimental, antes de se realizar a introdução dos queixadas.

Todos os comedouros foram vistoriados a cada dois dias (terças, quintas e sábados), estabelecendo-se quatro rotas para este monitoramento. Verificou-se a presença de pegadas de animais, fezes e mensurou-se o consumo de milho. Os comedouros foram monitorados de setembro de 1998 a junho de 2000, período de duração do experimento.

O consumo de milho foi medido através da introdução de uma régua de ferro dentro do tambor, com marcações de $1 \mathrm{~kg}$ em $1 \mathrm{~kg}$, permitindo-se determinar a quantidade de milho consumida (Figura 1). Os tambores foram reabastecidos quando a sobra registrada dentro do mesmo fosse menor ou igual a $30 \mathrm{~kg}$.

Através do monitoramento do consumo de milho nos comedouros teve-se, a partir do mês de abril de 1999 , conhecimento sobre quais deles eram mais freqüentados pelos animais, podendo-se iniciar a construção dos bretes para propiciar a recaptura dos queixadas.

A partir do mês de maio de 1999 , iniciou-se a coleta de dados referente ao ganho de peso dos

R. Bras. Zootec., v.32, n.1, p.191-199, 2003 


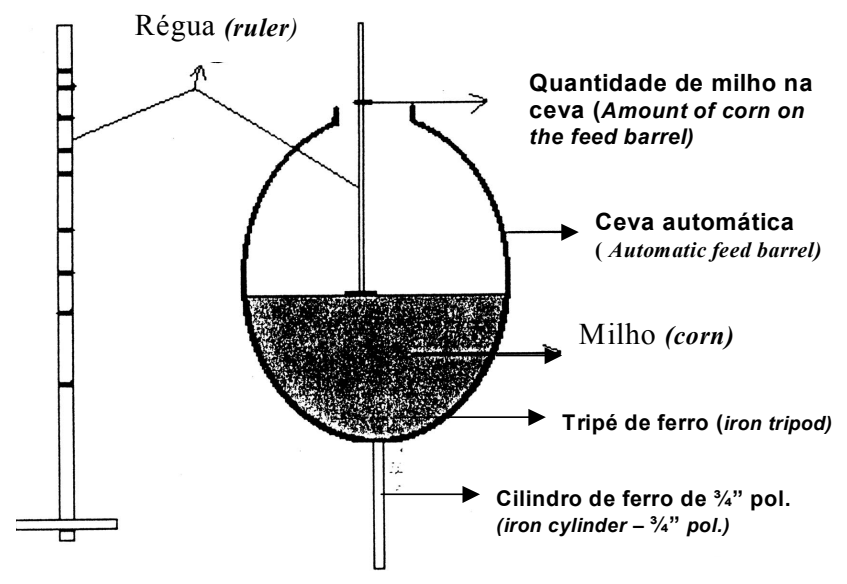

Figura 1 - Esquema demonstrativo para medir o milho consumido nos comedouros automáticos.

Figure 1 - Demonstrative diagram to measure the corn consumption on the automatic feed barrel.

animais com a conclusão do brete fixo no piquete (Comedouro $\mathrm{P}_{1}$ ).

Foram então construídos bretes fixos nos Comedouros 4A, 7A, 1B, 5B e 5D. No mês de outubro de 1999, todos os 5 bretes estavam instalados e as capturas foram intensificadas.

Os comedouros automáticos foram posicionados no centro dos bretes. Para facilitar a captura dos animais, espalhou-se o milho no interior do mesmo e na área externa em frente à porta basculante. Utilizaram-se duas formas para efetuar a captura dos queixadas. Na primeira, instalou-se um "trepeiro de observação", onde um observador se posicionou e pôde ver os animais se aproximando do brete e de onde, por meio de uma corda, desarmou-se a estrutura que mantinha a porta basculante aberta. Na segunda, que funcionou como armadilha, uma quantidade de milho foi espalhada no chão, logo abaixo de uma estrutura montada com varetas, que mantinha a corda que segurou a porta basculante aberta. Quando os animais atraídos pelo milho esbarraram nessa estrutura, a mesma foi desarmada e a porta se fechou.

Após a entrada dos animais no brete, o observador os encaminhou para a seringa. Para efetuar o manejo dos animais individualmente, colocou-se na saída da porta de guilhotina uma gaiola confeccionada em ferro, com tubo chato (metalão) de $0,60 \mathrm{~m}$ de largura, $0,60 \mathrm{~m}$ de altura e $0,80 \mathrm{~m}$ de comprimento, sendo que, na base dessa gaiola, acoplou-se um tablado de madeira. O peso da gaiola girou em torno de 43 a $45 \mathrm{~kg}$.

Ao sair da seringa, um animal de cada vez foi colocado dentro desta gaiola, onde foi pesado, identificado quanto ao sexo, idade aproximada e marcação individual, através de brinco e microchip.

O peso foi aferido em balanças de varão e para a pesagem dos filhotes, colocou-se os mesmos em sacos de milho vazios, pois as gaiolas permitiam sua fuga por entre as grades. Na oportunidade das recapturas, ainda, se observou dados como prenhez, perda de brincos e comportamento dos animais.

Os animais nascidos na área sofreram o mesmo manejo adotado para os animais anteriormente introduzidos.

\section{Resultados e Discussão}

\section{Consumo de milho e Ganho de peso}

O consumo de milho nos comedouros está ilustrado na Tabela 1. No piquete de 15 ha, este consumo apresentou um valor total de $7.244 \mathrm{~kg}$, consumo médio mensal de $329,27 \mathrm{~kg} \pm 119,81$ e coeficiente de variação de $36,4 \%$. Nos comedouros do sistema extensivo, o consumo médio mensal foi de $595,18 \mathrm{~kg}$ $\pm 322,11$ e coeficiente de variação de $54,1 \%$, o que indica que a dispersão dos dados em relação a média foi muito grande e pode ser explicada pela maior freqüência dos animais em determinados comedouros.

Na Figura 2, pode-se observar o consumo de milho por comedouro. Verificou-se maior freqüência e, por conseguinte, maior consumo nos comedouros $3 \mathrm{~A}$, $4 \mathrm{~A}, 7 \mathrm{~A}, 1 \mathrm{~B}, 5 \mathrm{~B}$ e $5 \mathrm{D}$, justamente naqueles onde

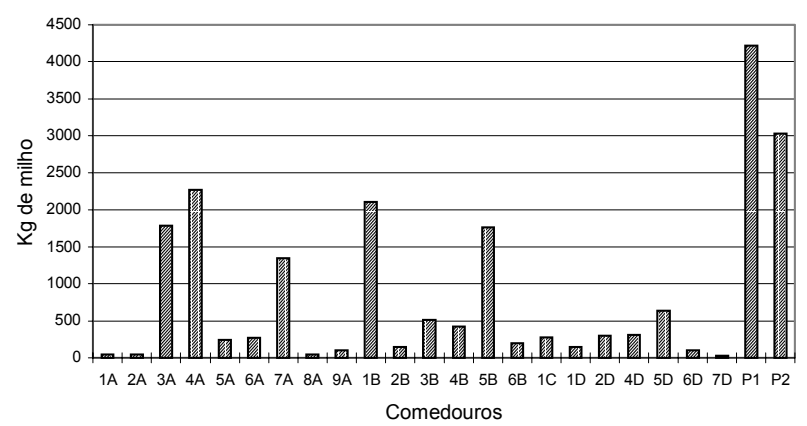

Figura 2 - Consumo de milho por comedouro (em kg) de set./98 a jun/00.

Figure 2 - Corn consumption on the automatic feed barrel $(\mathrm{kg})$ from Set/98 to Jun/00. 
Tabela 1 - Consumo de milho durante o período do experimento (22 meses)

Table 1 - Corn consumption during the experiment (22 months)

\begin{tabular}{lcccc}
\hline $\begin{array}{l}\text { Sistema } \\
\text { System }\end{array}$ & $\begin{array}{c}\text { Quantidade }(\mathrm{kg}) \\
\text { Quantity }(\mathrm{kg})\end{array}$ & $\begin{array}{c}\text { \% por sistema } \\
\% \text { per system }\end{array}$ & $\begin{array}{c}\text { Média mensal }(\mathrm{kg}) \\
\text { Monthly mean }(\mathrm{kg})\end{array}$ & $\mathrm{CV} *$ \\
$\begin{array}{l}\text { Semi-extensivo } \\
\text { Semi extensive }\end{array}$ & 7.244 & $35,6 \%$ & $329,27+119,81$ & $36,4 \%$ \\
$\begin{array}{l}\text { Extensivo } \\
\begin{array}{l}\text { Extensive } \\
\text { Total }\end{array}\end{array}$ & 13.094 & $64,4 \%$ & $595,18+322,11$ & $54,1 \%$ \\
\hline
\end{tabular}

${ }^{*}$ Coeficiente de variação (coefficient of variation).

foram implantados os bretes fixos para facilitar a recaptura. Por outro lado, houve comedouros onde o consumo praticamente não ocorreu. Notou-se também que o consumo de milho se iniciou dois meses após a introdução do primeiro grupo de queixadas (setembro de 1998).

Nas Figuras 3 e 4, pode-se observar o consumo de milho e a precipitação pluviométrica, no ano de 1999, nos dois sistemas de manejo utilizados. Correlacionando o consumo de milho com a época do ano, detectou-se que não houve correlação significativa $(\mathrm{r}=-0,12)$ para o período de seca (abril a setembro), nem para o período chuvoso (outubro a março).

Determinou-se que o consumo de milho foi superior no sistema extensivo, o que já era esperado devido ao maior número de indivíduos introduzidos, bem como, ao número de comedouros instalados. Quando se comparou a quantidade de milho consumido por animal em cada sistema (estimando-se uma população média de 20 animais no sistema semi-extensivo e de 95 animais no sistema extensivo, durante a maior parte do experimento - janeiro a dezembro de 1999), verificou-se que no sistema semi-extensivo cada indivíduo consumiu duas vezes mais a quantidade de milho do que aqueles manejados no sistema extensivo $(0,575 \mathrm{~kg}$ e $0,255 \mathrm{~kg}$, respectivamente).

A título de simulação foi avaliado também quanto de energia digestível(ED) foi suprida pelo milho consumido. Utilizou-se como referência para a quantidade de energia digestível necessária à manutenção da espécie, o valor de $150 \mathrm{kcal}$ de ED/kg de peso metabólico, que é a quantidade requerida para catetos em confinamento (Gallagher et al., 1984), espécie que pertence ao mesmo

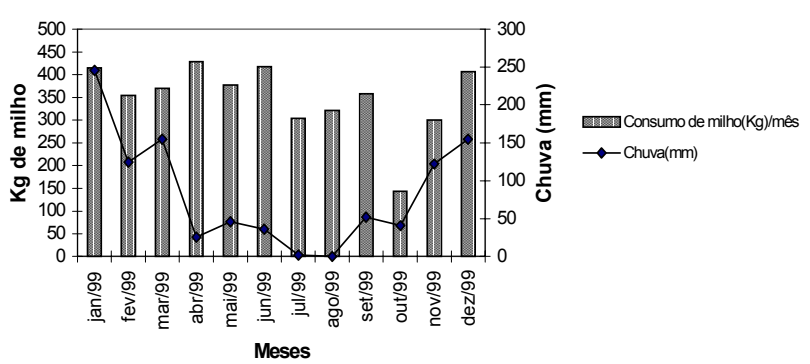

Figura 3 - Consumo de milho (kg) e precipitação pluviométrica $(\mathrm{mm})$ no período de um ano no sistema semi-extensivo.

Figure 3 - Corn consumption $(\mathrm{kg})$ and rainfall $(\mathrm{mm})$ during a year on the semi extensive system.

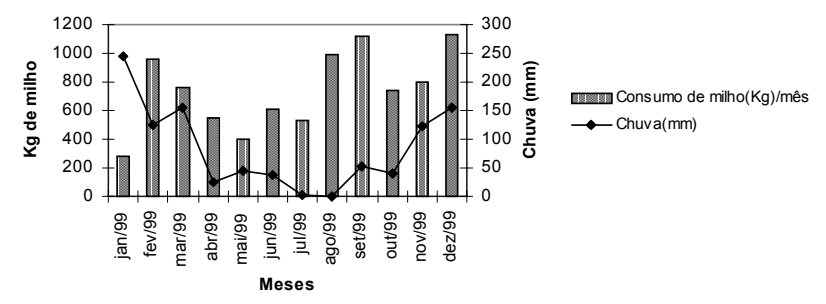

Figura 4 - Consumo de milho $(\mathrm{kg})$ e precipitação pluviométrica $(\mathrm{mm})$ no período de um ano no sistema extensivo.

Figure 4 - Corn consumption $(\mathrm{kg})$ and rainfall $(\mathrm{mm})$ during a year on the extensive system. 
gênero dos queixadas. Este requerimento, todavia, é subestimado, dado o maior porte dos queixadas e o intenso deslocamento destes na área experimental. $\mathrm{O}$ milho no sistema extensivo supriu aproximadamente $51 \%$ da ED requerida para manutenção dos queixadas e no sistema semi-extensivo, $98,6 \%$.

O consumo de milho no sistema extensivo demonstrou a importância de se fornecer um atrativo para animais transladados se habituarem a um novo ambiente, mas, representou também uma significativa fonte de energia digestível para os animais.

Neste experimento, também comparou-se o ganho de peso dos animais no sistema extensivo (tratamento 1) e no sistema semi-extensivo (tratamento 2). A análise dos dados deu-se através da comparação das médias de ganho de peso diário para as diferentes categorias, que foram: adulto, subadulto, jovem e filhote.

Os resultados apresentados na Tabela 3 demonstram que na categoria adulto, uma amostra de 48 indivíduos foi analisada, fornecendo um ganho de peso diário médio de $-0,51 \mathrm{~g} \pm 7,69$, no tratamento 1 , e $14,45 \mathrm{~g} \pm 10,87$, no tratamento 2 . Não houve diferença significativa entre o ganho de peso diário dos animais em liberdade e aqueles que foram mantidos no piquete. Precisa-se considerar, todavia, que o coeficiente de variação foi extremamente alto inviabilizando, de certa forma, o resultado da análise. No entanto, este resultado já era esperado, uma vez que fêmeas e machos foram analisados em conjunto e existiu uma grande oscilação do peso das fêmeas devido à entrada e saída do estado de prenhez na oportunidade das recapturas. Não foi possível isolar o fator sexo nesta análise, por ter sido pequena a amostragem de machos.

Para a categoria de filhote a amostra foi constituída de 18 indivíduos e o ganho de peso médio diário foi de $108,15 \mathrm{~g} \pm 16,19$, para o tratamento 1 , e 97,44 $\mathrm{g} \pm 22,88$, para o tratamento 2 . Também não houve diferença significativa neste caso e pode-se atribuir esse resultado ao fato de que nesta idade os animais ainda estão mamando, assim, o sistema de criação tem baixa influência no ganho de peso.

$\mathrm{Na}$ categoria jovem, a diferença também não foi significativa. Com uma amostra de 16 indivíduos, a média de ganho de peso diário foi de $114,30 \mathrm{~g} \pm 32,60$ para o tratamento $1, \mathrm{e} 77,02 \mathrm{~g} \pm 25,25$ para o tratamento 2 . Pode-se notar uma tendência de superioridade para o tratamento 1, quando comparadas essas médias, no entanto, o alto valor do coeficiente de variação $(\mathrm{CV}=87,76)$ pode ter mascarado o resultado.

Para a categoria subadulto $(n=43)$ o resultado apresentou-se significativo. O ganho de peso médio diário no tratamento 1 foi de $45,07 \mathrm{~g} \pm 5,04$ e no tratamento 2 de $25,37 \mathrm{~g} \pm 8,11$, indicando uma nítida superioridade para o tratamento 1 , ou seja, para o sistema extensivo.

Esse resultado sugere que o maior ganho de peso demonstrado no sistema extensivo deve-se principalmente a liberdade dos animais para o forrageio e para a obtenção de alimento natural, visto que o consumo de milho por animal foi menor nesse sistema. Os queixadas alimentam-se preferencialmente de frutos

Tabela 3 - Comparação de médias de ganho de peso diário (em g) Table 3 - Comparison of daily weight gain means $(g)$

\begin{tabular}{lccccc}
\hline $\begin{array}{l}\text { Categoria } \\
\text { Category }\end{array}$ & $\mathrm{n}^{1}$ & $\begin{array}{c}\text { Tratamento } 1^{2} \\
\text { Treatment } 1^{2}\end{array}$ & $\begin{array}{c}\text { Tratamento } 2^{2} \\
\text { Treatment } 2^{2}\end{array}$ & $\mathrm{CV}(\%)^{3}$ & $\mathrm{P}>\mathrm{F}^{4}$ \\
\hline $\begin{array}{l}\text { Adulto } \\
\begin{array}{l}\text { Adult } \\
\text { Filhote }\end{array}\end{array}$ & 48 & $-0,51+7,69$ & $14,45+10,87$ & 971,39 & 0,2670 \\
$\begin{array}{l}\text { Newborn } \\
\text { Jovem }\end{array}$ & 18 & $108,15+16,19$ & $97,44+22,88$ & 53,59 & 0,7074 \\
$\begin{array}{l}\text { Young } \\
\begin{array}{l}\text { Subadulto } \\
\text { Subadult }\end{array}\end{array}$ & 16 & $114,30+32,60$ & $77,02+25,25$ & 87,76 & 0,3813 \\
\hline
\end{tabular}

Tratamento 1 = sistema extensivo / Tratamento 2 = sistema semi-extensivo.

Treatment 1 = extensive system $/$ Treatment 2 = semi extensive system.

1 Tamanho da amostra (Sample size).

${ }^{2}$ Ganho de peso diário médio + erro-padrão da média, em gramas (daily weight gain mean \pm standard error, $g$ ).

${ }^{3}$ Coeficiente de variação (coefficient of variation).

${ }^{4}$ Teste $\mathrm{F}$ para comparação entre tratamento ( $\mathrm{F}$ test to compare treatments).

\section{R. Bras. Zootec., v.32, n.1, p.191-199, 2003}


e durante todo o ano houve disponibilidade destes nesta área de cerrado.

No sistema semi-extensivo, apesar da ingestão de uma quantidade de milho/animal duas vezes maior, o ganho de peso não superou os dos manejados em liberdade. A razão para esse resultado pode estar primeiramente na restrição de área a que foram submetidos e também pela alta energia digestível fornecida através do milho, que pode ter proporcionado um desestímulo à procura de outras fontes de alimento. Em suínos, quando a concentração de energia da dieta é alta, há uma diminuição no consumo de alimentos, em conseqüência, a ingestão de todos os outros nutrientes é afetada, incluindo os aminoácidos (Kansas, 1994, citado por Nutrição, 2001).

\section{Evolução do rebanho}

Através das recapturas conseguiu-se avaliar a evolução do rebanho. No sistema semi-extensivo foram totalizadas dez recapturas (intervalo de dois meses entre elas), cuja média de animais recapturados foi de 13,1 , sendo que, na última todos os animais (25) foram capturados e retirados do piquete. Nesta oportunidade detectou-se a entrada de dois machos no sistema.

Foram efetuadas 16 recapturas dos animais no sistema extensivo. A média de animais recapturados em cada uma dessas tentativas foi de 11,3 animais, sendo que, dos 69 indivíduos introduzidos, 39 animais foram avaliados pelo menos uma vez.

Apesar de todos os animais terem recebido duas marcações ao serem introduzidos, bem como os nascidos na área, houve perda de $14,3 \%$ dos brincos. No entanto, a leitura dos microchips pôde ser feita, garantindo a identificação de todos os animais.

\section{Sistema semi-extensivo}

Dos 13 indivíduos (três machos e dez fêmeas) introduzidos no piquete, apenas dez permaneceram até o fim do experimento. Este fato foi comprovado, pois, três fêmeas nunca foram recapturadas até o final do estudo, nem quando retiraram-se todos os indivíduos do piquete. Das fêmeas pertencentes ao grupo que permaneceram no piquete, cinco estavam prenhes quando foram introduzidas na área, sendo que três destas foram identificadas como as que se evadiram.

Constatou-se o nascimento de 14 indivíduos durante o período do experimento, e se conseguiu identificar as mães de 11 desses animais, sendo que os demais provavelmente eram crias das fêmeas que fugiram. A associação dos filhotes às suas respectivas mães se deu através da constatação da prenhez, da evolução do peso das fêmeas, do peso dos filhotes (Schaller, 1983) e da observação quanto ao comportamento dos diferentes indivíduos (fêmeas e filhotes) durante as recapturas. Muitas vezes observou-se os filhotes mamando e ocorreu também que estes, ao serem manejados antes das mães, esperaram por elas nas imediações do brete, emitindo sons. O oposto também ocorreu, ou seja, a fêmea após ser manejada e solta, permaneceu próxima ao brete aguardando seu filhote.

Duas fêmeas apresentaram duas parições durante o período do experimento, com intervalo de aproximadamente 16 meses (456 dias). Este é semelhante ao encontrado por Gottdenker \& Bodmer (1998) na Amazônia peruana, onde o intervalo de tempo entre o parto e a concepção foi de 250 dias, variando entre 192 e 331 dias, levando em consideração a duração de 157 dias para a gestação. No entanto, difere do resultado obtido por Nogueira-Filho \& Lavorenti (1997), que relataram para queixadas mantidas em cativeiro e tratadas com ração balanceada, um intervalo médio de partos de 203,37 $\pm 56,5$ dias.

Esse grande intervalo de tempo dos partos, sugere a não ocorrência do estro imediatamente após o parto, que pode ser devido à lactação. Em suínos, este fenômeno está associado à inibição do desenvolvimento do folículo ovariano e ao decréscimo da secreção gonadal (Dial \& Britt, 1986), e/ou a fatores como nutrição, doença, estresse e densidade. A nutrição parece ser uma causa relevante. Provavelmente uma dieta balanceada em proteína e energia proporcione uma diminuição do intervalo de tempo entre as parições.

Os nascimentos ocorreram nos meses de janeiro, março, junho, julho, setembro e novembro. Esse resultado demonstra não haver uma associação dos partos com as precipitações pluviométricas (Figura 5). A ocorrência de nascimentos durante todo o ano é similar ao relatado por Gottdenker \& Bodmer (1998), não havendo evidências de padrões sazonais para os partos.

Das sete fêmeas, que tiveram os filhotes identificados, quatro tiveram dois filhotes (um macho e uma fêmea), e as demais geraram cada uma, somente um filhote. Com isso, chegou-se a uma média de 1,57 filhotes produzidos por fêmea por parto. A proporção macho/fêmea nascidos foi de $1: 1$.

Ao final do experimento, retiraram-se 25 indivíduos, sendo 17 adultos, cinco subadultos, um jovem e dois filhotes; ou seja, no período de 22 meses a população no sistema semi-extensivo praticamente dobrou.

A produtividade bruta ( $\mathrm{n}^{\circ}$ de filhotes nascidos $/ \mathrm{n}^{\circ}$ de fêmeas adultas) neste sistema foi de 1,4 e a 
fecundidade bruta $\left(\mathrm{n}^{\circ}\right.$ de filhotes fêmeas nascidas $/ \mathrm{n}^{\circ}$ de fêmeas adultas) igual a 0,6 .

Esses resultados podem ser comparados com aqueles relatados por Nogueira-Filho \& Lavorenti (1997) e Bodmer (1989). A média obtida do número de filhotes por ninhada $(\mathrm{x}=1,57)$, se aproxima dos resultados encontrados por ambos autores, que relataram, respectivamente, médias de 1,71 para queixadas mantidos em cativeiro e 1,6 para indivíduos selvagens na Amazônia. Roots (1966) também identificou de um a dois filhotes por parição no Zoológico de Dudley.

A proporção obtida para machos e fêmeas nascidas por parto, de $50 \%$ para cada sexo, foi a mesma relatada por Gottdenker \& Bodmer (1998) na Amazônia peruana. Já a produtividade e a fecundidade bruta (1,4 e 0,6, respectivamente), apresentaram valores bem superiores àqueles reportados por esses autores, que obtiveram valores de 0,53 para produtividade bruta e, entre 0,32 e 0,26 para fecundidade bruta. Como o maior tamanho do grupo aumenta a competição direta e indireta entre as fêmeas, bem como também pela competição por alimento, o fato de ter-se trabalhado com um grupo pequeno, que ao final do experimento totalizava 25 indivíduos, deve ter influído para essa alta produtividade. Outro fator que deve ser considerado é que com a fuga de três fêmeas e a entrada de dois machos adultos no piquete, a proporção macho: fêmea no sistema, durante pelo menos doze meses, foi de 1: 1,4, ou seja cinco machos para sete fêmeas adultas. Supondo que não tenha sido estabelecida uma relação de dominância imediata e a não ocorrência de competição entre as fêmeas devido a disponibilidade de machos, estas podem ser as razões para uma produtividade bruta alta se comparadas aos resultados na Amazônia. Essa relação não foi mensurada para os grupos do sistema extensivo, pois não foram recapturados todos os animais, logo, a inferência correta quanto ao número de filhotes nascidos e o número de fêmeas adultas existentes na área não pôde ser obtida.

\section{Sistema extensivo}

Com relação aos grupos manejados no sistema extensivo, detectou-se o nascimento de 68 indivíduos (30 machos, 36 fêmeas e dois não identificados). Os partos ocorreram durante todo o ano (Figura 5), pois em cada recaptura havia sempre a presença de novos filhotes, jovens e subadultos. A identificação do filhote em relação a sua filiação, não foi possível ser feita para todos os animais nascidos, pois, em um

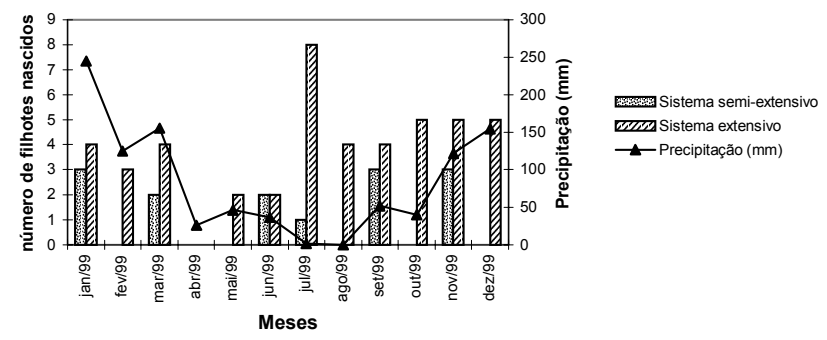

Figura 5 - Número de filhotes nascidos no sistema semiextensivo e extensivo e precipitação pluviométrica.

Figure 5 - Number of newborn animals on semi extensive and extensive system and the rainfall.

sistema aberto pode ocorrer a mistura de grupos nas recapturas, e essa identificação resulta numa margem de erro muito grande.

Ao final do experimento, testaram-se três modelos para estimar o tamanho da população de queixadas em liberdade na área da fazenda. Todos eles baseados na metodologia de marcação e recaptura; o modelo de Petersen, o modelo de Jolly-Seber e o modelo de Schnabel (Sutherland, 1996). O modelo que se mostrou mais adequado a este experimento foi o de Schnabel, pois assume as mesmas suposições que o modelo de Petersen, ou seja, que todos os animais são igualmente recapturáveis, que todos animais marcados e não marcados morrem ou deixam a área na mesma taxa e que nenhuma marca é perdida. No entanto, o modelo de Schnabel é utilizado quando os animais são capturados em várias ocasiões, o que ocorreu neste experimento. Desta forma a população estimada ao final do experimento foi de 149 indivíduos (69 introduzidos inicialmente), com um intervalo de confiança ao limite de $95 \%$, entre 136 e 164 indivíduos.

\section{Conclusões}

A técnica de utilização de comedouros automáticos e bretes para recaptura é eficaz para o manejo e controle de queixadas mantidas em sistemas extensivo e semi-extensivo. O milho em grão, nesses sistemas, serve não só como um atrativo para os animais silvestres, mas também como fonte suplementar de energia.

O sistema extensivo se mostra mais vantajoso que o semi-extensivo para o manejo de queixadas. Ele pode ser utilizado para a exploração sustentável da espécie, em comunidades isoladas, que praticam a caça de subsistência. 


\section{Literatura Citada}

BODMER, R.E. Ungulate biomass in relation to feeding strategy within Amazonian forests. Oecologia, v.81, n.1, p.547-550, 1989.

Managing Amazonian wildlife: biological correlates of game choice by detribalized hunters. Ecological Applications, v.5, n.1, p.872-877, 1995.

DIAL, G.; BRITT, J.H. Clinical endocrinology of reproduction in the pig. In: MORROW, D.A. (Eds.). Current therapy in theriogenology. Philadelphia: W. B. Saunders, 1986. p.905-911.

GALLAGHER, J.F.; VARNER, L.W.; GRANT, W.E. Nutrition of the collared peccary in south Texas. Journal Wildlife Management., v.48, n.3, p.748-761, 1984.

GOTTDENKER, N.; BODMER, R. Reproduction and productivity of white-lipped and collared peccaries in the Peruvian Amazon. Journal of Zoology, v.245, n.1, p.423-430, 1998.

KILTIE, R.A. Bite force as a basis for niche differentiation between rainforest peccaries (Tayassu tajacu and Tayassu pecari). Biotropica, v.14, n.1, p.188-195, 1982.

KILTIE, R.A.; TERBORGH, J. Observation on the behaviour of rainforest peccaries in Peru: why do white-lipped peccary form herds? Zoological Tierpychol, v.62, n.1, p.241-255, 1983.

MAYER, J.J.; WETZEL, R.M. Tayassu pecari. Mammalian Species, v.293, n.1, p.1-7, 1987.

NOGUEIRA-FILHO, S.L.G.; LAVORENTI, A. O manejo do caitetu (Tayassu tajacu) e do queixada (Tayassu pecari) em cativeiro. In: PÁDUA, C.V.; BODMER, R.E. (Eds.) Manejo e conservação de vida silvestre no Brasil. Brasília: $\mathrm{CNPq}$ / Belém: Sociedade Civil Mamirauá, 1997. p.106-115.
NUTRIÇÃO. [on line] Disponível na Internet via WWW. URL: http://www.porkworld.com.br/producao/nutricao. Html. Arquivo capturado em 07 de maio de 2001.

REDFORD, K.H.; ROBINSON, J.G. Sustainable harvest of neotropical forest animal. In: REDFORD, K.H.; ROBINSON, J.G. (Eds.). Neotropical wildlife use and conservation. Chicago: University of Chicago Press, 1991. p.415-429.

ROOTS, C.G. Notes on the breeding of the white-lipped peccaries (T. albirostris) at Dudley Zoo. International Zoological Year Book. The Zoological Society of London, 1966. v.6, n.1, p.198-199.

SCHALLER, G.B. Mammals and their biomass on a Brazilian Ranch. Arquivos de Zoologia, v.31, n.1, p.1-36, 1983.

SOWLS, L.K. The peccaries. 1.ed. Texas, USA: University of Arizona Press, 1984. 251 p.

SUTHERLAND, W.J. Ecological census techniques: a handbook. Cambridge University Press, 1996. p.17-54.

Recebido em: 20/06/01

Aceito em: 06/09/02 